\title{
Long-term maintenance of increased exercise involvement following a self-management intervention for housebound older adults with arthritis
}

\author{
Kareen Nour*1, Sophie Laforest ${ }^{2}$, Lise Gauvin ${ }^{3}$ and Monique Gignac ${ }^{4}$
}

\begin{abstract}
Address: ${ }^{1}$ Centre de recherche et d'expertise en gérontologie sociale (CREGES), CSSS Cavendish-Centre Affilié Universitaire, Montreal, Quebec, Canada, ${ }^{2}$ Department of Kinesiology, University of Montreal; Associate Researcher, Groupe de recherche interdisciplinaire en santé (GRIS), University of Montreal, and Centre de recherche et d'expertise en gérontologie sociale(CREGES), CSSS Cavendish-Centre Affilié Universitaire, Montreal, Quebec, Canada, ${ }^{3}$ Department of Social and Preventive Medicine, University of Montreal; Associate Researcher, Groupe de recherche interdisciplinaire en santé (GRIS), University of Montreal; Researcher, The Léa-Roback Centre on Social Inequalities of Health in Montreal, Montreal, Quebec, Canada and ${ }^{4}$ Health Care \& Outcomes Research, University Health Network \& Associate Professor, Department of Public Health Sciences, University of Toronto, Toronto, Ontario, Canada
\end{abstract}

Email: Kareen Nour* - kareen.nour.cvd@ssss.gouv.qc.ca; Sophie Laforest - sophie.laforest@umontreal.ca;

Lise Gauvin - lise.gauvin.2@umontreal.ca; Monique Gignac - gignac@uhnres.utoronto.ca

* Corresponding author

Published: 4 June 2007

International Journal of Behavioral Nutrition and Physical Activity 2007, 4:22 doi:10.1 186/1479. Accepted: 4 June 2007

$5868-4-22$

This article is available from: http://www.ijbnpa.org/content/4/I/22

(C) 2007 Nour et al; licensee BioMed Central Ltd.

This is an Open Access article distributed under the terms of the Creative Commons Attribution License (http://creativecommons.org/licenses/by/2.0), which permits unrestricted use, distribution, and reproduction in any medium, provided the original work is properly cited.

\begin{abstract}
Background: Sustained maintenance of health behaviors is a determinant of successful symptom reduction strategies for older adults with arthritis. This study examined whether or not short-term improvements in exercise involvement were maintained 8 months following a home-based arthritis self-management intervention as well as the moderating role of individual characteristics in the maintenance of behavior change.

Methods: Of the II 3 housebound older adult participants at pre-intervention, 97 completed the post-intervention interview, and 80 completed the 8-month post-intervention interview.

Results: Some post-intervention improvements in exercise involvement were maintained 8 months later. More specifically, weekly exercise frequency, particularly regarding walking frequency, and variety of exercise activities were still significantly greater in the experimental group than in the control group 8 months following the completion of the intervention. No moderating influences were observed for any of the individual characteristics.
\end{abstract}

Conclusion: We conclude that gains in exercise involvement achieved through a self-management intervention can be maintained 8 months following the intervention.

\section{Background}

Community-based arthritis self-management interventions have been shown to have significant short-term benefits on health status $[1,2]$ as well as on adoption and maintenance of health behaviors among older popula- tions with arthritis [1,3-8]. Although regular involvement in health behaviors is recognized as a crucial element in successful symptom-reduction strategies $[9,10]$, very little is known about the extent to which self-management interventions result in sustained behavior change [11-16]. 
The present follow-up study examined whether or not short-term gains after a home-based self-management arthritis intervention called I' $m$ Taking Charge of $M y$ Arthritis! [17] were maintained 8 months later. A previous study examining short-term behavior changes following the intervention through a randomized controlled trial (RCT) showed that homebound older adults participants increased frequency of exercise involvement (walking and stretching exercises) as well as variety of exercises [18]. The current follow up study also explored the potential moderating role of participants' socio-demographic [19-21], . psychological [22-25]., and physical characteristics [26] on maintenance of behavior change [27]. This second aim is of particular relevance because examination of the short-term impact of the intervention showed that participants with lower income had smaller intervention gains than more affluent individuals, and those with depression experienced no gains, in contrast to non-depressed participants who showed improvements [18].

The few studies having examined long-term maintenance of intervention effects show mixed results [11-15]. For example, Fries et al. [15] showed limited or no long-term maintenance of exercise frequency. Barlow et al [14] observed that individuals with arthritis who participated in a community-based self-management intervention successfully maintained changes in communication with physician, use of strategies of distraction and visualization, performance of relaxation and flexibility exercises at 4 and 12 months post-intervention. Conversely, Lindroth et al[12] found that among rheumatoid arthritis (RA) participants, frequency of practice was not maintained either at 12 months post-intervention or 5 years later [13]. Finally, the only study evaluating maintenance of changes from a home-based arthritis intervention showed that improvements in frequency of walking and level of household and self-care activities were maintained [16] for RA participants at 12 and 52 weeks post-intervention.

\section{Methods}

Details of the methods and selection of participants have been reported elsewhere [18] but are summarized briefly below.

\section{Procedures}

Eight trained interviewers administered questionnaires to participants in their homes. They were blind to group allocation and to the intervention's specific objectives. Interviews were used to measure all variables and lasted about two hours. Interviews were conducted upon recruitment (baseline), 8 weeks later prior to randomization (preintervention), upon completion of the intervention (postintervention-1) and 8 month post-intervention (postintervention-2). In most cases (75\%), the same interviewer performed all four interviews with participants.
The ethics committee of the CSSS Cavendish approved the study and participants signed an informed consent form prior to involvement.

\section{Participants and design}

One hundred and twenty five older housebound adults living with osteoarthritis or rheumatoid arthritis composed the initial sample. Between baseline and pre-intervention measurements, 12 participants dropped out. From the 113 remaining participants, 65 were randomly assigned to an experimental and 48 to a one-year wait list control group. Due to dropout, 97 completed the postintervention-1 measures (experimental, $\mathrm{n}=58$; wait list control, $\mathrm{n}=39$ ) and 80 completed the post-intervention2 measures (experimental, $\mathrm{n}=50$; wait list control, $\mathrm{n}=$ 30). Persons dropping-out between the pre-intervention and post-intervention-1 measure $(n=16)$ reported fewer everyday coping behaviors and higher depression levels than those who persisted. The 17 participants who dropped out between the two post-intervention measures reported less variety in their exercises in comparison to those who persisted in the study. Reasons for dropping out from post-intervention-1 to post-intervention- 2 were related to health related problems (e. g., needed hospitalization, deterioration of health status) or to housing (e.g., moving to a seniors residence). To our knowledge, only one participant dropped out due to study burden. Finally, no statistically significant differences in sociodemographic variables were observed between the initial sample of 113 participants and the 80 participants persisting in the study (results not shown).

\section{Intervention}

Participants in the experimental group participated in an intervention called I'm Taking Charge of my Arthritis ! $[17,28]$. This intervention consisted of six sessions of onehour done in the participant's home by a trained health care practitioner. Each visit included a review of the previous visit, an exploration of a new topic, and the formulation of a new personal contract. A variety of procedures was used to ensure practitioner reliability in intervention implementation [see [18]].

\section{Post-intervention follow-up}

Following the intervention, a subset of the experimental group $(n=29)$ received social reinforcement through bimonthly support telephone calls for a period of 6 months whereas the remaining experimental participants $(n=39)$ did not receive this support. Preliminary analyses indicated that this reinforcement did not have a significant impact on the health and the health behaviors of participants. Therefore, both groups were merged into one experimental group for examination of the effects of the intervention on maintenance. No visits from the interviewer or the interventionists were conducted either in the 
experimental or control groups. Moreover, no phone calls from the research team to participants were made during this period. Therefore, no actual observations were made and no data were collected in regard to the health or the health behaviors of participants.

\section{Variables and measures}

For the current study, only those outcome variables that showed significant changes immediately following the intervention [18] were examined, namely frequency and variety of exercise involvement. Conceptually this choice is appropriate because the focus of the current study is on maintenance of change rendering examination of variables not showing change incongruous. Empirically, preliminary analyses showed that those variables not influenced by the intervention between baseline and postintervention-1 remained unchanged 8 months later (at post-intervention-2) (results not shown). Data on sociodemographic characteristics were collected at baseline and information on physical and psychological characteristics was collected at pre-intervention. Data on exercise involvement were recorded at all four measurement times.

\section{Outcomes variables}

Exercise was categorized into three broad types of activity: walking, stretching, and strengthening. Participants were asked to estimate the number of times per week they performed each activity (from 0 to 7 times/week). A composite of the total weekly occurrence of exercise was calculated by adding the weekly frequencies of the 3 types of activities. Scores could range from 0 to 21 (sum of the 3 activities for 7 days). An index of the variety of activities adopted was computed by dividing the number of exercise activities reported for each type of exercise by the total number of exercises possible and then multiplied by 100 (score varying from $0 \%$ to $100 \%$ ).

\section{Confounding variables}

Perceived socioeconomic status [29,30], level of education, age, living situation, and gender were self-reported. Type of arthritis was recorded by the case manager. A composite physical factor (from - 1 to +1 ) was created through a factor score resulting from factor analysis of various scales that evaluated pain intensity, fatigue, $(0-100$ VAS)[13] limitations and stiffness (0-5 WOMAC)[31]. Those scales were used in various study on with arthritis individuals [6,32-34]. Higher scores on the factor reflected greater disability. Finally, a composite psychological factor was created through a factor score resulting from another factor analysis of measures of optimism (15 scale) [35], mastery (1-5 scale)[36], and self-efficacy (0-100 SES)[37]. Higher scores on the psychological factor reflected greater psychological health. Depression was evaluated by the CES-D [38]. Participants were dichot- omized into depressed (mean scores of 16 or above out of 60) and not depressed.

\section{Statistical analyses}

We applied multilevel modeling techniques to overcome the challenges presented by the data set (e.g., different initial and final sample sizes) and the advantages related to theses techniques (e.g., inclusion of data from all participants collected at any time). The goals of the data analysis were to determine if the intervention resulted in a longterm maintenance of (a) the weekly frequency of exercise (strengthening, stretching, and walking) activities and (b) the variety of exercises, despite controlling for potential confounding effects. A secondary aim consisted of exploring whether or not there were any moderating influences of individual characteristics.

Analyses were performed with SPSS (version 10) and HLM 5.04 (Hierarchical Linear Modeling, Scientific Software International, Chicago, IL). A first set of analyses included parameters operationalizing time and group membership in order to explore whether or not there were changes across time and as a function of group membership. Second and third sets of analyses were performed by adding possible confounding variables to the models in order to examine whether or not intervention effects were maintained despite controlling for possible confounders. For moderating effects, interaction terms between group membership and depression or socioeconomic status were created and entered into the model both with and without control for confounding variables. Significant interactions were plotted to allow for interpretation.

\section{Results}

Of the 113 participants $(M=77.7$ years, $S D=10.3)$ at preintervention, $90 \%$ were women, with less than 9 years of education (47\%). About $71 \%$ lived alone. Sixty-three percent of participants had been diagnosed with OA and $83 \%$ reported that they were financially comfortable. Participants who completed the post-intervention-2 measurement $(n=80)$ were, on the whole, similar to participants who had been randomized at pre-intervention $(n=113)$. They were aged 76.6 years olds ( $\mathrm{SD}=11.0$ ), 89\% were women and $74 \%$ lived alone. All participants' characteristics at pre-intervention are presented in Table 1. A more exhaustive descriptive profile of the sample is available elsewhere [8,39].

Table 2 shows the observed values and relative increases in outcome measures for experimental and control groups at different times. Results of the multilevel modeling analyses are described below and appear in Table 3.

In terms of the first objective, namely to examine whether or not short-term gains after a self management arthritis 
Table I: Demographic characteristics of participants.

\begin{tabular}{|c|c|c|c|}
\hline & Pre-intervention participants & Post-intervention participants & Post-intervention2 participants \\
\hline & $N=1 / 3 M(S D)$ or $\%$ & $N=97 M(S D)$ or $\%$ & $N=80 M(S D)$ or $\%$ \\
\hline Age (years) & $77.70(10.31)$ & $77.27(10.67)$ & $76.61(10.99)$ \\
\hline Women $(\%)$ & 90.3 & 90.7 & 88.8 \\
\hline Poor/very poor self-reported economic statues & 18.6 & 17.5 & 17.5 \\
\hline Education (years) & $9.33(4.11)$ & $9.21(4.04)$ & $9.32(3.8 I)$ \\
\hline Living alone (\%) & 70.8 & 71.1 & 73.8 \\
\hline Osteoarthritis & 62.8 & 62.9 & 63.8 \\
\hline No depression (> 16 on 60 ) & 41.4 & 42.7 & 42.3 \\
\hline
\end{tabular}

intervention were maintained at 8 months, results showed that the weekly occurrence of exercise was maintained 8 months after completion of the intervention ( $\mathrm{p}=$ .05) even though data show a decrease in exercise involvement across time for experimental group participants. That is, experimental participants decreased their mean weekly occurrence of exercise from 10.02 times per week immediately following the intervention to 7.04 times per week at 8-months after the intervention while control participants' frequency of involvement in exercise changed from 5.64 times per week to 6.17 times per week. Nevertheless, multilevel modeling analyses showed that the decrease in the experimental group was not large enough to obviate between-group differences, suggesting the maintenance of effects $(p=.05)$ after the end of the program.

The variety of exercises were maintained 8 months after completion of the intervention $(\mathrm{p}=.05)$. Although experimental participants decreased slightly their mean variety of exercises from $63 \%$ immediately following the intervention to $60 \%$ at 8 -months post-intervention, control participants' increased their variety of exercises from $41 \%$ to $43 \%$. Multilevel modeling analyses showed that the variety of exercises was maintained across time $(\mathrm{p}=.01)$.

Analyses of the three types of exercises showed that the weekly frequency of walking activity was maintained $(\mathrm{p}=$
.05), but that the frequency of stretching exercises was not $(\mathrm{p}=.50)$. In fact, the mean walking frequency of experimental participants increased in the 8 month period from 2.57 times per week to 2.76 times per week while the frequency of walking of control group participants increased from 1.72 times per week to 1.93 times per week. Multilevel modeling analyses indicated that walking frequency was maintained across time and that differences between the groups were still statistically significant $(\mathrm{p}=.01)$. However, during the same period, there was a significant decrease in experimental participants' frequency of stretching exercises from 4.57 times per week to 2.80 times per week. As a result, frequency of stretching exercises was not maintained $(\mathrm{p}=.50)$. The weekly frequency of strengthening exercises, which did not change immediately following the intervention, remained unchanged in long term $(\mathrm{p}=.51)$. These findings were not altered after controlling for confounding variables.

In terms of the second goal, namely to explore the potential moderating role of participants' sociodemographic, psychological., and physical characteristics on maintenance of behaviour change, no significant results were obtained as none of the interaction terms achieved statistical significance. The findings suggest the absence of any moderating influences of age, gender, education, living arrangements, physical symptoms and disability, and psy-

Table 2: Observed Means and Relative Increases in Outcome Variables at Different Times for each Group

\begin{tabular}{|c|c|c|c|c|c|c|c|c|c|c|c|}
\hline \multirow{2}{*}{$\begin{array}{l}\text { Measurement time } \\
\text { Outcome variables }\end{array}$} & \multicolumn{3}{|c|}{ Baseline } & \multicolumn{2}{|c|}{$\begin{array}{c}\text { Pre- } \\
\text { intervention }\end{array}$} & \multicolumn{2}{|c|}{$\begin{array}{l}\text { Post- } \\
\text { intervention-I }\end{array}$} & \multicolumn{2}{|c|}{$\begin{array}{l}\text { Post- } \\
\text { intervention-2 }\end{array}$} & \multicolumn{2}{|c|}{$\%$ increase (post2-post I/postl) } \\
\hline & Max & Exp. & Control & Exp. & Control & Exp. & Control & Exp. & Control & Exp. & Control \\
\hline \multicolumn{12}{|l|}{ Group } \\
\hline Variety of exercises & 100 & 47 & 49 & 47 & 38 & 63 & 41 & 60 & 43 & -4.76 & 4.87 \\
\hline Occurrence of exercises (times/week) & 21 & 7.35 & 7.12 & 6.48 & 4.79 & 10.02 & 5.64 & 7.04 & 6.17 & -29.74 & 9.40 \\
\hline - stretching (times/week) & 7 & 2.85 & 2.73 & 2.56 & 2.06 & 4.57 & 2.30 & 2.80 & 3.03 & -38.73 & 31.74 \\
\hline - walking (times/week) & 7 & 2.26 & 2.83 & 2.04 & 1.77 & 2.57 & 1.72 & 2.76 & 1.93 & 7.40 & 12.21 \\
\hline - strengthening (time/week) & 7 & 2.25 & 1.56 & 1.87 & .96 & 2.88 & 1.61 & 1.48 & 1.90 & -48.61 & 18.01 \\
\hline
\end{tabular}


Table 3: Hierarchical Linear Models Analyses Predicting Exercise Change and Maintenance following the Intervention

\begin{tabular}{|c|c|c|c|c|c|c|c|c|c|c|c|c|c|c|c|}
\hline \multirow[b]{2}{*}{ Within-Subject Fixed Effects } & & \multicolumn{3}{|c|}{ Baseline } & \multicolumn{3}{|c|}{ Pre-intervention } & \multicolumn{4}{|c|}{ Post-intervention I } & \multicolumn{4}{|c|}{ Post-intervention 2} \\
\hline & & $\gamma_{i j}$ & Coeff. & $S E$ & $\gamma_{i j}$ & Coeff. & SE & $\gamma_{i j}$ & Coeff. & $S E$ & $p$ & $\gamma_{i j}$ & Coeff. & SE & $p^{a}$ \\
\hline \multirow[t]{2}{*}{ Variety of exercises } & Intercept & $\gamma_{00}$ & .51 & .04 & $\gamma_{10}$ & -.14 & .05 & $\gamma_{20}$ & -.10 & .05 & .08 & $\gamma_{30}$ & -.10 & .05 & .12 \\
\hline & Group & $\gamma_{01}$ & -.03 & .06 & $\gamma_{11}$ & .13 & .06 & $\gamma_{21}$ & .24 & .06 & .00 & $\gamma_{31}$ & .22 & .07 & .00 \\
\hline \multirow[t]{2}{*}{ Occurrence of exercise } & Intercept & $\gamma_{00}$ & 7.78 & .83 & $\gamma_{10}$ & -3.00 & .86 & $\gamma_{20}$ & -2.33 & 0.92 & .01 & $\gamma_{30}$ & -2.31 & 1.02 & .02 \\
\hline & Group & $\gamma_{01}$ & -.97 & 1.10 & $\gamma_{11}$ & 2.40 & 1.13 & $\gamma_{21}$ & 5.23 & 1.19 & .00 & $\gamma_{31}$ & 2.54 & 1.30 & .05 \\
\hline \multirow[t]{2}{*}{ - stretching } & Intercept & $\gamma_{00}$ & 3.12 & .38 & $\gamma_{10}$ & -1.06 & .42 & $\gamma_{20}$ & -.87 & .45 & .06 & $\gamma_{30}$ & -.45 & .50 & .37 \\
\hline & Group & $\gamma_{01}$ & -.40 & .50 & $\gamma_{11}$ & .76 & .56 & $\gamma_{21}$ & 2.63 & .59 & .00 & $\gamma_{31}$ & .44 & .64 & .50 \\
\hline \multirow[t]{2}{*}{ - walking } & Intercept & $\gamma_{00}$ & 2.67 & .36 & $\gamma_{10}$ & -.90 & .42 & $\gamma_{20}$ & -.99 & .45 & .03 & $\gamma_{30}$ & -1.12 & .50 & .03 \\
\hline & Group & $\gamma_{01}$ & -.56 & .48 & $\gamma_{11}$ & .79 & .56 & $\gamma_{21}$ & 1.35 & .59 & .02 & $\gamma_{31}$ & -1.59 & .64 & .01 \\
\hline \multirow[t]{2}{*}{ - strengthening } & Intercept & $\gamma_{00}$ & 2.00 & .36 & $\gamma_{10}$ & -1.00 & .39 & $\gamma_{20}$ & -.39 & .41 & .30 & $\gamma_{30}$ & -.69 & .46 & .14 \\
\hline & Group & $\gamma_{01}$ & -0.01 & .47 & $\gamma_{11}$ & 1.09 & .51 & $\gamma_{21}$ & .91 & .53 & .10 & $\gamma_{31}$ & .39 & .59 & .51 \\
\hline
\end{tabular}

Statistical significance of coefficient $\gamma_{31}$ is indicative of maintenance effects using the following model:

Level I model: Outcome $=\beta_{0 j}+\beta_{1 j} X_{1}+\beta_{2 j} X_{2}+\beta_{2 j} X_{2}+r_{i j}$

Level 2 model: $\mathrm{T}_{1} \beta_{0 \mathrm{j}}=\gamma_{00}+\gamma_{01} \mathrm{Gr}_{\mathrm{j}}+\mathrm{u}_{\mathrm{oj}}$

$\mathrm{T}_{2} \beta_{\mathrm{li}}=\gamma_{10}+\gamma_{11} \mathrm{Gr}_{\mathrm{i}}$

$\mathrm{T}_{3} \beta_{2 \mathrm{j}}=\gamma_{20}+\gamma_{21} \mathrm{Gr}_{\mathrm{j}}$
$\mathrm{T}_{4} \beta_{2 \mathrm{i}}=\gamma_{30}+\gamma_{31} \mathrm{Gr}_{\mathrm{j}}$

where i: I ....N individuals; $r_{i j:}$ level I error term ; $\gamma_{i j}$ : coefficients for parameters ; $u_{\mathrm{oj}}$ level-2 random effect ; $\beta$ : coefficient ; Gr: group membership

$(I=$ experimental, $0=$ control $) ; X_{1}$ : dummy variable $(I=$ pre-intervention, $0=$ otherwise $) ; X_{2}$ : dummy variable $(I=$ post-intervention- $I, 0=$

otherwise); $\mathrm{X}_{3}$ : dummy variable $(\mathrm{I}=$ post-intervention- $2,0=$ otherwise $)$

Meaning of Coefficients:

$\gamma_{00}=$ Predicted value in outcome variable at baseline for participants in control group

$\gamma_{01} \mathrm{Gr}_{\mathrm{i}}=$ Predicted difference in outcome variable at baseline for participants in experimental group

$\gamma_{10}=$ Predicted change in outcome variable from baseline to pre-intervention for participants in control group

$\gamma_{1 /} \mathrm{Gr}_{\mathrm{j}}=$ Predicted difference in change in outcome variable from baseline to pre-intervention for participants in experimental group

$\gamma_{20}=$ Predicted change in outcome variable from baseline to post-intervention I for participants in control group

$\gamma_{21} \mathrm{Gr}_{j}=$ Predicted difference in change in outcome variable from baseline to post-intervention-I for participants in experimental group

$\gamma_{30}=$ Predicted change in outcome variable from baseline to post-intervention-2 for participants in control

$\gamma_{31} \mathrm{Gr}_{\mathrm{j}}=$ Predicted difference in change in outcome variable from baseline to post-intervention-2 for participants in experimental group.

${ }^{a}$ significance of the changes that had occurred between post-intervention-I and post-intervention- 2

chological health. That is, changes were maintained across a diverse range of groups.

\section{Discussion}

This study examined whether or not short-term improvements in exercise involvement were maintained 8 months following a home-based arthritis self-management intervention as well as the moderating role of individual characteristics in the maintenance of behavior change. Results showed that behavior changes observed immediately after the self-management intervention for variety and frequency of exercise were maintained 8 months following completion of the intervention despite apparent decreases in exercise involvement. Furthermore, long-term maintenance was not moderated by individual characteristics. Among the three subtypes of exercises assessed, only changes in walking remained statistically significant with participants reporting walking even more frequently 8months after the program.

These results are congruent with some studies on maintenance of involvement in exercise after self-management interventions $[4,16]$. Given the rigorous study design, we propose that maintenance is related directly to the "quality of the content" of the intervention [40-42]. First, participants were strongly encouraged to take daily walks in their homes and immediate surroundings. They were shown, during the intervention, that walking is an "easyto-do" exercise that can be performed anywhere, at any time. This demonstration and the verbal persuasion may have supported participants in their maintenance of exercise. Secondly, participants highly valued "increasing walking frequency or distance" in the personal contracts implemented during the intervention. Given that these contracts stay with participants after the intervention as "reminder" of the importance of staying active, they might have supported their exercise maintenance. Finally, during the intervention, participants received an exercise hand-out with examples of stretching and strengthening exercises. Even though these types of exercises were not maintained across time, this sheet might also been an exercise "reminder" which might have influence exercise maintenance. Together, the hand-out, the encouragement received, and the personal contract may have had a longterm impact on motivating people to stay active, to get out of the home, and even to use resources to exercise. 
However, given that maintenance of intervention changes are usually precarious, other strategies could be implemented. First, even if social reinforcement by interventionists did not have significant impact on exercise maintenance, we propose that such reinforcement should be delivered by the practitioner intervening with participants because interventionists are the ones who know and understand participants and with whom the participant shares a bond of trust. Secondly, new exercise information could be sent periodically to participants in order to strengthen the value of staying physically active as well as to provide a new series of home exercises. Finally, considering the absence of maintenance of stretching and strengthening activities, the new version of the I'm Taking Charge of My Arthritis! intervention, now includes additional hand-out exercise sheets. In fact, it is possible that participants became bored with repeating the same six stretching and strengthening activities provided on the exercise hand-out and decided to walk instead because it is easier and more pleasant. These changes may help future participants maintain intervention benefits.

In addition to the previous results, it also interesting to note that even though short-term changes in weekly exercise frequency were moderated by economic status and depression, no individual characteristics played a moderating role in the maintenance process. This finding is in contrast to others studies [41] who highlight functional limitations, comorbid situation, depressives symptoms, gender $[43,44]$, self-efficacy, and perceived behavioral control [45-47] as predictors of maintenance of health behavior. Such results have important implications for setting and timing of intervention. In fact, our long-term results imply that when interventions result in changes, everyone, regardless of their individual characteristics can maintain them.

Despite these findings and interpretations, several limitations of the study should be mentioned. Participants may have demonstrated social desirability bias in responding to interviews and thus reported more exercise than they actually performed. Similarly, other variables not measured in our study (i.e., social support by the family or involvement in other activities) might explain greater maintenance of exercise involvement. Furthermore, limitations to the RCT were discussed elsewhere [18] and included the self-reported measures and the relatively small number of participants. Additional limitations are the long-term follow-up wherein no experimental manipulation was done between post-intervention- 1 and postintervention-2, which limits interpretation of the findings. Furthermore, the sample of the current study was composed predominantly of females and thus calls into question its generalizability. However, as other studies have shown [12-15], females are more likely to suffer from arthritis than males (54\% versus 37\% in Canada for older adults) thus likening the study context to a realworld situation.

Nevertheless, considering the frail and housebound nature of the target population and the large variety of positive impacts exercise can have on their health, the current findings remain encouraging. Moreover, the low to moderate levels of pre-intervention exercise of this population and the significant improvements and some longterm maintenance of exercise behaviors support the notion that providing such interventions on a wider scale could have significant benefits in the management of disability. Interventions at home may facilitate learning and adoption of health behaviors.

To our knowledge, this is the only study conducted entirely on housebound older adults with arthritis for the purpose of evaluating a home-based self-management intervention. Health promotion interventions such as I'm Taking Charge of My Arthritis! can support the plight of homebound older adults with arthritis who must deal with arthritis symptoms on a daily basis.

\section{Competing interests}

The author(s) declare that they have no competing interests.

\section{Authors' contributions}

Kareen Nour and Sophie Laforest conceptualized the research project, participated in the design of the study and wrote the article. Kareen Nour further developed the ideas and the statistical analysis and coordinated the gathering of data. Sophie Laforest, as principal researcher of the project I'm Taking Charge of My Arthritis!, undertook the general supervision of the project and actively participated in each step. Lise Gauvin guided the statistical analysis and contributed to the conceptualization and writeup of the manuscript. Monique Gignac made a significant contribution to writing of the article, through a critical review of the intellectual content. All authors read and approved the final manuscript.

\section{Acknowledgements}

This research was funded by Canadian Health Institutes of Research Grant \#MOP-42547. At the time of writing the manuscript, Kareen Nour held a doctoral fellowship from the Fonds de la recherche en santé du Québec, Government of Quebec. We would like to thank the participants, Silvia Straka, Richard Goudreault of the Direction de santé publique de Montréal, collaborating CLSCs, and members of the Advisory Committee for their contributions to this research.

\section{References}

I. Barlow JH, Williams B, Wright CC: Instilling the strength to fight the pain and get on with life: learning to become an arthritis self-manager through an adult education programme. Health Education Research 1999, I4(4):533-44. 
2. Lorig K, Sobel DS, Stewart AL, et al:: Evidence suggesting that chronic disease self-management programme can improve health status while reducing hospitalization. Medical Care 1999, 37(I):5-14.

3. Goeppinger J, Lorig K: Interventions to reduce the impact of chronic disease: Community-based arthritis patient education. Annual Review of Nursing Research 1997, I5:101-22.

4. Barlow JH, Turner AP, Wright CC: Long-term outcome of an arthritis self-management programme. British Journal of Rheumatology 1998, 37:1315-9.

5. Goeppinger J, Mcnee C, Anderson K, Boutaugh M, Steward K: From research to practice: The effects of the jointly sponsored dissemination of an arthritis self-care nursing intervention. Applied Nursing Research 1989, 8(3): 106-13.

6. Bell MJ, Lineker SC, Wilkins AL, Goldsmith $\mathrm{CH}$, Badley EM: A randomized controlled trial to evaluate the efficacy of community bases on physical therapy in the treatment of people with rheumatoid arthritis. Journal of Rheumatology 1998, 25(2):23I-7.

7. Keefe FJ, Caldwell L: Cognitive behavioral control of arthritis pain. Advances in Rheumatology 1997, 8 I (I):277-90.

8. Nour K, Laforest S, Gignac M, Gauvin L: Appreciating the Predicament of Housebound Older Adults with Arthritis. Canadian Journal on Aging 2005, 24(I):57-70.

9. Albright $G L$, Fischer $A A$ : Effects of warming imagery aimed at trigger-point sites on tissue compliance, skin temperature, and pain sensitivity in biofeedback-trained patients with chronic pain: A preliminary study. Perceptual \& Motor Skills 1990, 7I(3): II 63-70.

10. Lorig K, Holman $\mathrm{H}$ : Arthritis self-management studies: A twelve years review. Health Education Quarterly 1993, 20(I): 17-28.

II. Lineker SC, Badley EM, Hughes A, Bell MJ: Development of an instrument to measure knowledge in individuals with rheumatoid arthritis: The ACREU Rheumatoid Arthritis Knowledge Questionnaire. Journal of Rheumatology 1997, 24:647-53.

12. Lindroth $Y$, Brattstöm M, Bellman I, et al.: A problem-based education program for patient with rheumatoid arthritis: Evaluation after three and twelve months. Arthritis Care and Research 1997, I0(5):325-32

13. Lindroth Y, Bauman A, Brooks P, Priestley D: A 5-year follow-up of a controlled trial of an arthritis education program. British Journal of Rheumatology 1995, 34(4):647-52.

14. Barlow $\mathrm{JH}$, Wright CC: Knowledge in patients with rheumatoid arthritis: A long term follow-up of a randomizatised controlled study of patients education leaflets. British Journal of Rheumatology 1998, 37:37I-6.

15. Fries JF, Carey C, McShane DJ: Patients education in arthritis: Randomised controlled trail of a mail-delivery program. Journal of Rheumatology 1996, 24:1378-83.

16. Lineker SC, Bell MJ, Wilkins AL, Badley EM: Improvements following short term home based physical therapy are maintained at one year in people with moderate to severe rheumatoid arthritis. Journal of Rheumatology 200I, 28:165-8.

17. Laforest $S$, Nour K, Parisien M, et al.: «Mon arthrite, je m'en charge !». Aperçu du développement, de l'implantation et de l'évaluation d'un programme d'autogestion de la douleur chez des personnes âgées arthritiques confinées a la maison. Vie et Vieillissement 200।, 3(3-7):

18. Nour K, Laforest S, Gauvin L, Gignac M: Behavior change following a self-management intervention for housebound older adults with arthritis: an experimental study. International Journal of Behavioral Nutrition and Physical Activity 2006:3-12.

19. Wade TJ, Cairney J: The effect of sociodemographics, social stressors, health status and psychosocial resources on ageddepression relationship. Canadian Journal of Public Health 2000, 9I(4):307-12.

20. Mackenbach JP, Borsboom G], Nusselder WJ, Looman CW, Schrijvers CT: Determinants of levels and changes of physical functioning in chronically ill persons: results from the GLOBE Study. Journal of Epidemiology and Community Health 200I, 55(9):63I-8.

21. Bauman AE, Sallis JF, Dzewaltowski DA, Owen N: Toward a better understanding of the influences on physical activity: The role of determinants, correlates, causal variables, mediators, moderators, and confounders. American Journal of Preventive Medecine 2002, 23(2 Suppl):5-I4.
22. Gignac MAM, Cott CA, Badley EM: Adaptation to chronic illness and disability and its relationship to perceptions of independence and dependence. Journal of Gerontology: Psychological Sciences 2000, 55B:362-72.

23. Fermia EE, Zarit SH, Johansson B: Predicting change in activities of daily living: a longitudinal study of the oldest in Sweden. Journal of Gerontology B. Psychology Science and Sociology Science 1997, 52(6):294-302.

24. Baranowski T, Anderson C, Carmack C: Mediating variable framework in physical activity interventions: How are we doing? How might we do better? American Journal of Preventive Medicine 1998, 15:266-97.

25. Rhee SH, Parker JC, Smarr KL, et al.: Stress management in rheumatoid arthritis: What is the underlying mechanism? Arthritis Care and Research 2000, I3(6):435-42.

26. Clark NM, Becker MH, Janz NA, Rakowski WAL: Self-management of chronic disease by older adults. Journal of Aging and Health I99|, 3(I):3-27.

27. Jette $A$, Rooks $D$, Lachman M: Home-based resistance training: Predictors of participation and adherence. Gerontologist 1998, 38(4):4|2-2|.

28. Laforest S, Parisien M: I'm taking charge of $m y$ arthritis website. 2005 [http://www.myarthritis.ca:].

29. Daveluy C, Pica L, Audet N, Courtemanche R, Lapointe F, Côté L: Enquête sociale et de santé 1998 - Cahier technique et méthodologique : documentation générale. Institut national de santé publique, Montréal, Canada 200I.

30. Daveluy C, Audet N, Courtemanche R, Lapointe F, Côté L, Baulne J: Méthodes. Institut national de santé publique, Montréal, Canada: 2000

31. Bellamy N, Watson H, Buchanan W, Goldsmith CH, Campbell J, Stitt LW: Validation study of WOMAC: A health status instrument for measuring clinically important patient relevant outcome to antirheumatic drug therapy in patients with osteoarthritis of the hip or knee. Journal of Rheumatology 1988, 15:1833-40

32. Taal E, Rasker JJ, Seydel ER, Weigman O: Health status, adherence with health recommandations, self-efficacy and social support in patient with rheumatoid arthritis. Patient Education and Counselling 1993, 20:63-76.

33. Lorig K, Seleznick M, Lubeck D, Ung E, Chastain RL, Holman HR: The beneficial outcomes of the arthritis self-management course are not adequately explained by behavior change. Arthritis and Rheumatism 1989, 32(I):91-5.

34. Barlow JH, Turner AP, Wright CC: A randomized controlled study of the arthritis self-management programme in UK. Health Education Research 2000, 15(6):665-80.

35. Pearlin LI, Schooler C: The structure of coping. Journal of Health and Social Behavior 1978, 19:2-21.

36. Scheier MF, Carver CS: Optimism, coping, and health: Assessment and implications of generalized outcome expectancies. Health Psychology 1985, 4(3):219-47.

37. Lorig K, Chasteain RL, Ung E, Shoor S, Holman HR: Development and evaluation of a scale to measure perceived self-efficacy in people with arthritis. Arthritis and Rheumatism 1989, 32(i):37-44.

38. Blalock SJ, DeVellis RF, Brown GK, Wallston KA: Validity of the center for epidemiological studies depression scale in arthritis population. Arthritis and Rheumatology 1989, 32(8):991-7.

39. Nour K, Laflamme V, Laforest S, Gignac M, Bouchard L: Importance des exercices physiques et de relaxation dans le cadre d'un programme d'autogestion de la douleur. Vie et Vieillissement 2005, 4(3): |6-2|.

40. Newman S, Mulligan K, Steed L: What is meant by self-management and how can its efficacy be established? Rheumatology (Oxford) 200I, 40(I): I-4.

4I. Minor MA, Brown JD: Exercise maintenance of persons with arthritis after participation in class experience. Health Education Quarterly 1993, 20(I):83-95.

42. Stiggelbout M, Hopman-Rock M, Crone M, Lechner L, Lvan Mechelen $W$ : Predicting older adults' maintenance in exercise participation using an integrated social psychological model. Health Education Research 2006, 21:1-14.

43. Dunlop DD, Semanik P, Song J, Manheim LM, Shih V, RW Chang: Risk Factors for Functional Decline in Older Adults with Arthritis. Arthritis Rheum 2005, 52(4): I274- I 282. 
44. Walsh JME, Rogot Pressman A, Cauley JA, Browner W: Predictors of Physical Activity in Community-dwelling Elderly White Women. Gen Intern Med 200I, I 6(II):72I-727.

45. Armitage C]: Can the Theory of Planned Behavior Predict the Maintenance of Physical Activity? Health Psychology 2005, 24:235-245.

46. Livanou M, Baoglu M, Marks IM, De Silva P, Noshirvani H, Lovell K, Thrasher S: Beliefs, sense of control and treatment outcome in post-traumatic stress disorder. Psychological 2002, 32:157-165.

47. Solomon K, Annis HM: Outcome and efficacy expectancy in the prediction of post-treatment drinking behaviour. Addiction 1990, 85(5):659-665.

Publish with Bio Med Central and every scientist can read your work free of charge

"BioMed Central will be the most significant development for disseminating the results of biomedical research in our lifetime. "

Sir Paul Nurse, Cancer Research UK

Your research papers will be:

- available free of charge to the entire biomedical community

- peer reviewed and published immediately upon acceptance

- cited in PubMed and archived on PubMed Central

- yours - you keep the copyright

Submit your manuscript here:

http://www.biomedcentral.com/info/publishing_adv.asp 